Santa Clara University

Scholar Commons

Management

Leavey School of Business

$2-1992$

\title{
Building top management muscle in a slow growth environment: How different is better at Greyhound Financial Corporation
}

Gregory B. Northcraft

Terri L. Griffith

Santa Clara University, tgriffith@scu.edu

Christina E. Shalley

Follow this and additional works at: https://scholarcommons.scu.edu/mgmt

Part of the Business Administration, Management, and Operations Commons

\section{Recommended Citation}

Northcraft, G.B., Griffith, T.L., \& Shalley, C.E. (1992). Building top management muscle in a slow growth environment: How different is better at Greyhound Financial Corporation. Academy of Management Executive, 6, 32-41.

Copyright $(1992$ Academy of Management. Reprinted with permission.

This Article is brought to you for free and open access by the Leavey School of Business at Scholar Commons. It has been accepted for inclusion in Management by an authorized administrator of Scholar Commons. For more information, please contact rscroggin@scu.edu. 


\section{Building top management muscle in a slow growth environment: how different is better at Greyhound Financial Corporation}

Gregory B. Northcraft, University of Arizona

Terri L. Griffith, University of Arizona

Christina E. Shalley, University of Arizona

Executive Overview
The turbulence experienced in the 1980 s in the U.S. business environment has led to something of a motivational crisis among corporate managers.

Increased competition, budget constraints, and changing demographics are forcing companies into adopting strategies geared toward downsizing and flatter organizational structures. While corporate America probably has begun to accept its leaner profile, it has not yet successfully addressed the issue of how to keep the best managerial talent "tuned in and turned on" in an era of dwindling resources.

This article describes and assesses one corporation's efforts to maintain top-managerial motivation through a unique form of job swapping called the "Muscle Building" program at Greyhound Financial Corporation in Phoenix, Arizona. Muscle building, a top-management job rotation program, helps prevent career gridlock, fosters management diversity, and provides for top-management succession. "Hidden" costs and benefits of the program and issues concerning its implementation are discussed.
Article

The 1980s may well go down in history as the "decade of downsizing"-a time of turbulence and belt-tightening in which many U.S. corporations went from comfortable to concerned and substantially trimmed their ranks to remain competitive. General Motors, for instance, cut 150,000 jobs from its payroll-about twenty-five percent of all jobs-during the 1980s. In one two-month period in 1989, five of America's top corporations-Campbell Soup, Chrysler, Kodak, RJR Nabisco, and Sears-cut a total of 13,000 jobs among them. ' United States corporate giants such as DuPont and Hughes Aircraft have slimmed down and flattened organizational charts by cutting out layers of management resulting in the disappearance of one of every four middle-management positions since $1980 .^{2}$

It is hardly surprising that this turbulence has led to something of a motivational crisis within the management ranks in U.S. corporations. The prospect of layoffs or salary cuts means that employees of large corporations now see their organizations as less loyal to them, and in turn feel less loyalty to their organizations. ${ }^{3}$ Furthermore, trimming corporate hierarchies has important implications even for those who escape the corporate axe-namely, fewer opportunities and more competition for them. 
Since 1980, the time between promotions for promising managers has probably doubled, ${ }^{4}$ and the opportunities for managers to advance their salaries have diminished substantially. These factors have no doubt contributed to low morale among managers and executives. For instance, a Korn/Ferry-UCLA survey of 700 U.S. managers revealed that nearly seventy percent of the respondents were dissatisfied with their current responsibilities and accomplishments. ${ }^{5}$ Overall, while corporate America probably has begun to accept its leaner profile, it has not yet successfully addressed the issue of how to keep the best managerial talent "tuned in and turned on" in an era of dwindling resources.

Many corporations have begun to experiment with ways to create substitutes for corporate "fast tracks." At Hyatt Corp, stalled staffers are being encouraged to come up with ideas for free-standing new lines of business within the company ${ }^{6}$ DuPont and Merck are providing a change of pace for their fast-trackers by sending them back to school, or to new assignments overseas. ${ }^{7}$ G.S.I. Transcomm Data Systems in Pittsburgh staves off career boredom by inviting its employees to redefine their roles and expand their responsibilities. ${ }^{8}$ Reassignment of managers who have reached a career plateau to head blue-ribbon task forces or run local charities also are possibilities. ${ }^{9}$

Some companies - and even one state government ${ }^{10}$ - have begun to experiment with lateral job transfers as a means for satisfying the hungers of their most promising managerial talent. ${ }^{11}$ This article describes and assesses one corporation's efforts to maintain top-managerial motivation through a unique form of job swapping called the "Muscle Building" program at Greyhound Financial Corporation in Phoenix, Arizona. The case information is based on interviews with the company president, all seven program participants, and several program non-participants (supervisors and subordinates of "muscle builders").

\section{Greyhound Financial-Some Background}

Greyhound Financial Corporation (GFC) has been a wholly-owned subsidiary of corporate giant Dial Corp since 1962. GFC began as a leasing company, and since has expanded into corporate finance, providing secured financing to commercial clients whose needs are too specialized for local banks and too small to interest large financial institutions. Because GFC is in a substantially different type of business than any of Dial Corp's other divisions, GFC enjoys quite a bit of operational autonomy.

Like many corporations, GFC suffered through dramatic turbulence during the 1980s. Changes in the U.S. business environment-specifically, tax law changes which made leasing a less-profitable line of business-and a major fraud perpetrated in 1985 by one of GFC's long-standing clients led to a downturn in the company's fortunes. Decreasing business activity necessitated a reduction in GFC's workforce from 230 employees in 1985 to its current size of 150 employees. Several top-management personnel were let go, and the parent corporation even attempted to sell off GFC, without success, in 1986. Not surprisingly, morale at GFC in the mid-1980s was quite low.

Sam Eichenfield was hired as GFC's new president in 1987, and immediately began taking decisive steps to alter the company's structure and operations. GFC began to move away from corporate leasing toward corporate financing, a new incentive structure was put in place, and a more participative approach to organizational problem-solving (one involving employee problem-solving groups working with an outside consultant) was initiated. One of Eichenfield's key changes at the top of the organization was the introduction of a "muscle-building" program. 12 


\section{Although some additional training might also be arranged if the new position warrants it, the majority of muscle builders' learning and development is expected to occur "on the job."}

\section{"Muscle building" at GFC}

Corporate "muscle building" was introduced via a memo from Eichenfield to all GFC employees in 1988. The focus of his memo was "How do we make GFC stronger?" The memo noted that traditionally, making GFC stronger had simply meant plugging up obvious holes-filling open positions by promoting from within or (when no current employee was a logical choice) by recruiting externally. Eichenfield's new "muscle-building" program would take a different approach. It would create new opportunities at GFC by moving people around.

The muscle-building program had two principal components: selection and placement. The initial memo stated that participants selected for the program would be top-rated executive managers at GFC (e.g., assistant vice-presidents) who had been in their current positions a couple of years or longer, and who had conspicuously demonstrated (through their work) high development potential. They would be placed in departments doing tasks different from those in their background and experience. Furthermore, the new program would not necessarily wait for openings to occur naturally in high-profile jobs. Instead, top managers identified for the program would simply "swap" jobs.

Three muscle-building moves were made in the first implementation of the program in June 1988. An assistant VP in the corporate treasury was moved to an opening in marketing, and two assistant VPs in Administrative Services and Corporate Planning swapped jobs. These initial muscle-building assignments reflected not only Eichenfield's assessment of the development potential of the participants, but also his sense that there was enough overlap between the swapped jobs, or between the participants' past experiences and new assignments, to make for successful (if not smooth) transitions. In both 1989 and 1990, two pair of VPs swapped jobs.

The 1990 phase of the program involved more daring job trades-swaps for which participants had little direct past experience relevant to the new position. For example, a direct job trade was made between the director of Human Resources Management and the assistant vice-president of Real Estate Receivables (a CPA loan-administration manager). It is expected that the number of new muscle builders added to the program each year (two to four) will remain low, both to maintain stability in the company and because muscle building really isn't right for everyone-just the highest potential people at GFC.

Two of the program's implementation specifics - timing and personal rewards for participants-bear mentioning. The timing of the job swaps, when they begin and when they end, has been negotiated between Eichenfield and each participant. Eichenfield noted that the swaps typically do not occur immediately on announcement, but neither is the idea that the participants are allowed to work up to the change during an extended period (such as six months). In most cases, the two muscle builders swapping jobs work each other into their new jobs over a period of several weeks or a few months. In at least one case (the swap between Real Estate Receivables VP and the HRM director) one of the muscle builders thought that learning-by-doing and asking for help when needed would provide the most effective "breaking-in." So she pushed up the timetable and jumped whole hog into her new job. Although some additional training might also be arranged if the new position warrants it, the majority of muscle builders' learning and development is expected to occur "on the job."

The time horizon of the swaps may be the most fascinating aspect of the program. Muscle building at GFC is not just a way of experiencing a different side of the business for a short time. Eichenfield noted that most of the new assignments are intended to be for at least a couple of years-long enough for muscle builders to really learn and excel in a new position. One participant asked to remain 
permanently in a job she was muscle built into because it turned out to be a great position for her. Eichenfield agreed to her request, since it appears to be a good outcome for the company. However, the majority of program participants must assume that once identified as muscle builders, they will continue to receive new assignments every few years. After all, part of the intent of the program is that muscle builders continue to learn and develop beyond the learning associated with any single job.

\begin{abstract}
However, muscle building is not temporary reassignment; it is a form of career alteration. Implicit in the program is the lack of a "safety net"-for either the individual or the company. Once jobs are swapped, a muscle builder has no job to fall back on if the new job doesn't work out. The old job is filled, usually by another muscle builder. Nor is the time horizon sufficiently short that a muscle builder can just try to "get through it." Thus, there is a strong incentive for a muscle builder to excel and contribute in the new function and it is important for GFC to identify muscle builders who will adapt and succeed.
\end{abstract}

The policies concerning personal rewards for participants have evolved with time. The swapped jobs do not always have either the same hierarchical status within GFC, or the same associated compensation. To address this issue, it was decided that all muscle builders would maintain their titles (e.g., assistant VP) as they moved through assignments in the program. Similarly, muscle builders retain the basic compensation package associated with their assignment when they become a muscle builder. The rationale for these arrangements is that muscle builders should be participating in the program for development rather than monetary gain. (However, all muscle builders' salaries are reviewed and adjusted immediately prior to their first job swap, to insure that their compensation is up to date.)

Not surprisingly, this policy has bothered muscle builders who are given lower-status job assignments, or are asked to take on more responsibilities than their compensation would appear to warrant. While this may be a problem in the short term, the core philosophy of muscle building is that managerial growth occurs through all types of job swaps (e.g., upward, lateral, downward). Therefore, a participant's current position or short-term compensation should be less of a concern than whether that participant is continuing to learn and develop. Moreover, Eichenfield believes that during the course of several muscle-building assignments, these apparent inequities will even out for program participants.

\title{
Program Benefits
}

Programs like GFC's muscle building might be viewed as the inevitable consequence of economic developments in the 1980s. Certainly the flattening of organizations for economic reasons has created a fair amount of career "gridlock" 13 - dwindling opportunities for high potential managers (HIPOs) to move up. ${ }^{14}$ Furthermore, in a world of flatter organizations, those few opportunities to move up that do arise may be bigger jumps - riskier for the company and for the manager. This is forcing organizations to find new ways to satisfy the ambitions and maintain the interest of their HIPOs. One survey found that twenty-eight percent of its companies had only limited opportunities available for HIPOs because of internal politics, slow growth, or poor succession planning and twenty-eight percent also reported losing HIPOs because adequate HIPO identification practices were absent. ${ }^{15}$ Moreover, these problems are probably exacerbated by changing demographics: thanks to the impending managerial maturation of the "baby boom" generation, there are probably more highly-qualified managers now competing for those few promotional opportunities making corporate pyramids more clogged than ever. ${ }^{16}$ 
Muscle building addresses the career gridlock problem in two ways. First, muscle building acknowledges HIPOs. The designation "muscle builder" makes sure GFC's HIPOs know that the company realizes their value and that they will be advanced when opportunities arise. Second, muscle building maintains the interest and motivation of GFC's HIPOs by giving them new challenges. For instance, one muscle builder at GFC thought that the program was her salvation in the company. Her boss was only slightly older than she, and it was clear that she could not move up until he did, which was not anticipated in the near future. She felt that she was facing long-term career gridlock that muscle building alleviated-good for her (she is now a much happier employee) and good for the company (she didn't leave).

Beyond economic pressures to create a substitute for the "corporate fast-track," GFC's muscle-building program addresses three problems that plague organizations even in the best of times: individual career plateauing, organizational creativity, and organizational succession planning.

Individual career plateauing Career gridlock is not the only form of career plateauing faced by HIPOs. It is a form of structural plateauing - a problem created by an organization's structure that leaves nowhere for movers and shakers to go. Even when there are opportunities for HIPOs to move up in an organization, content plateauing can occur. When a manager has mastered the tasks of a job or functional area to the point where the tasks have become routine or repetitive, the manager becomes stagnant. $^{17}$

\section{Beyond economic pressures to create a substitute for the "corporate fast-track," GFC's muscle- building program addresses two problems that plague organizations even in the best of times: individual career plateauing, and organizational succession planning.}

Content plateauing raises the issue that the development of HIPOs requires not only new challenges on a regular basis, but probably different challenges as well. Researchers have noted the dangers of "homosocial reproduction"- the tendency of companies to develop new managers that look like and share the perspectives of the current batch of top people. ${ }^{18}$ This also may be a problem within functional areas of a company. Programs like muscle building force managers to alter and even challenge their routines and providing a healthy diversity of experience across functional areas that should promote the development of managerial potential.

Muscle building at GFC provides experience diversity through lateral job movement. Muscle building is a form of job rotation for top management. ${ }^{19}$ In the survey mentioned earlier, eighty-four percent of companies reported using some variant of job rotation as a form of HIPO development. ${ }^{20}$ However, those companies also reported that in many cases HIPOs found their job switches to be too rapid (i.e., not enough time spent in rotated jobs), thereby fostering a lack of accountability. In effect, the time frame was obviously short enough that HIPOs might focus only on short-term accomplishments, or even just try to survive the job rather than fully engaging it. The result would be exposure to other jobs, but a failure both to really learn (in-depth) from the rotation experience and to be committed to succeeding in the job. Muscle building at GFC appears to have avoided these pitfalls by having unspecified time frames within job assignments, and by not guaranteeing any future availability of the muscle-builder's old job.

Organizational creativity

Besides contributing to management development, muscle building represents a potential way to increase employee's creativity. Creativity no doubt will prove to be a key element in corporate America's attempts to compete more effectively in the world marketplace. Recognizing this, researchers have begun to focus on how organizations can enhance their creative and innovative capabilities. ${ }^{21}$ 


\section{While creativity cannot be forced, muscle building does encourage creativity by putting managers in circumstances where their own tried-and-true routines are unlikely to apply.}

Organizational creativity requires that individuals (1) possess a broad base of knowledge, (2) draw upon that base to develop novel approaches to different situations, and (3) have the opportunity and motivation to take calculated risks testing out their novel approaches. ${ }^{22}$ While creativity cannot be forced, muscle building does encourage creativity by putting managers in circumstances where their own tried-and-true routines are unlikely to apply. Inevitably, muscle building expands managers' base of knowledge and experience, but also forces managers to confront the risks of trying new approaches to doing things. Thus, muscle building enhances GFC's creative potential by expanding the knowledge base among participants, and cultivating in them a healthy appreciation of their ability to take risks-and make those risks pay off.

\section{Succession Planning}

In terms of succession planning, developing future leadership potential is a key top management function. ${ }^{23}$ Often too much emphasis in succession planning may be placed on identification of HIPOs, rather than on their development once identified. Rotational development programs like GFC's help HIPOs gain an organizational perspective-a better understanding of how all the pieces of the organization work together - and allow HIPOs to develop relationships with key players across the organization. Individuals with this experience provide excellent CEO material.

Interestingly, Eichenfield has decided that a position in corporate strategy will

alwarys be part of the muscle building rotation. This ensures that all of GFC's best managerial talent will have both an understanding of the corporate planning function, and (at some point) a hand in helping to develop it. Thus, muscle building satisfies the corporate agenda by providing well-rounded succession candidates, and a process by which their adaptability can be monitored and even developed.

Increased diversity of perspective really captures the thrust of muscle building as articulated by Eichenfield in his initial 1988 memo. Eichenfield envisioned muscle building as a way to give GFC's best managers exposure to more of the company than would traditionally occur, in the belief that GFC would benefit from the application of new insights developed from new and broader perspectives. In short, muscle building would make GFC's best managerial talent stronger, and make the company stronger.

\section{Some Hidden Benefits}

In addition to the three major benefits of muscle building outlined previously - alleviating gridlock, promoting perspective diversity, and developing succession material-GFC found several "hidden benefits" in its program. Developing increased loyalty from GFC's highest potential executive material is an additional benefit. One participant in the program specifically noted that muscle building had dramatically increased his marketability to other corporations, including GFC competitors. He also noted, however, that as long as GFC's muscle-building program continued to provide him new and different challenges, he would have no reason to look for employment elsewhere. This is an important benefit for GFC, coming at a time when companies are bemoaning the lack of loyalty among employees, and salary compression problems often reinforce company hopping.

A significant short-term benefit of muscle building is job redefinition and redesign. The contrast of new perspectives from different functional areas encourages muscle builders to think about new ways to do their new jobs. There may even be some demand for muscle builders to seek out ways to improve their new jobs, as 


\section{Muscle building specifically encourages its participants to work closely together during the job swap phase, fostering a climate of teamwork among GFC's high potential managers, in place of the traditional cutthroat "tournament" model of corporate advancement.}

a way of making a contribution in the new position. Muscle builders are probably in a better position to suggest these improvements than either incumbents (who may be too deeply steeped in the job's routines) or new hires (whose lack of familiarity with the company as a whole could lead to less valuable suggestions). Eichenfield noted that this was precisely why it was important for muscle builders to work quickly into their new jobs. That avoids socialization into the traditional way of doing the job. As an example, the muscle builder who assumed the HRM directorship learned in her first month on the job that a form she used to labor over in the loan department was simply filed and never used. She immediately streamlined the process. Socialized into the HRM perspective, she might have accepted the inevitability of the prior procedure.

While confidence and adaptability are important prerequisites for admission into GFC's muscle-building program, it is also clear that muscle building strengthens these critical managerial characteristics. Several participants indicated that having survived a muscle-building experience, confidence in their ability to accept new and totally different career responsibilities had increased. Muscle building may serve the same developmental role as rotating manufacturing line-managers into headquarters, or giving headquarter executives the opportunity to "start-up" a new plant. As noted earlier, muscle builders may be more likely to accept or take risks; no doubt they will prove highly adaptable in the face of major organizational or environmental changes.

The most subtle benefits of muscle building at GFC concern the changes that have occurred in its culture, both for participants and non-participants. One of the principal advantages of rotational development programs is the creation of a strong peer network among an organization's HIPOs. ${ }^{24}$ Muscle building specifically encourages its participants to work closely together during the job swap phase, fostering a climate of teamwork among GFC's high potential managers, in place of the traditional cutthroat "tournament" model of corporate advancement. ${ }^{25}$ Because movement in muscle building is lateral, it lessens the sense of competition in the management ranks.

For non-participants in the program, muscle building puts subordinates in the position of helping train their bosses. Often this means that muscle builders are forced to delegate some of their responsibilities simply because they are not yet aware of how to fulfill them. As a result, it is not only the muscle builders whose muscles are being built. The program also provides their subordinates with valuable developmental experiences. This is comparable to the "hidden benefits" of limited amounts of absenteeism and turnover-namely, those left must learn to carry on.

\section{Some Questions}

The primary issue about the program voiced by GFC's muscle-building participants involved potential for disruption by using a job-rotational management development program. Several aspects of this were discussed. The issue most often raised was the learning curve associated with accepting a new job assignment. Any form of job rotation will necessitate a learning period in which performance may be diminished. Muscle building, because it involves job swaps across functional areas may intensify this problem. However, any form of management development that entails learning must allow for some margin of poor performance or even failure.

For the immediate boss of a muscle builder (or even the immediate subordinate), learning curve failures can create a frustrating experience-one that reflects negatively on the non-participants' performance as well as on muscle builders'. Eichenfield contends that this is simply part of gaining long-term management 


\section{However, one must wonder what the long-term career path for a muscle builder looks like.}

development benefits. GFC has yet to experience a real failure of a muscle builder in a new job assignment. Eichenfield believes that careful selection of program participants is the key to avoiding this possibility.

Career disruption-both for participants and non-participants - is another issue raised by the presence of any job rotation management development program like muscle building. Muscle building allows a larger cohort of HIPOs to remain satisfied with their career progress, but it also leaves each participant to wonder where his/her career might have gone in the meantime. This becomes an especially poignant issue when a muscle builder is moved into a lower-status or high-responsibility position without the title or additional compensation.

(Interestingly, muscle builders' subordinates also raised this issue: If I have to train my boss, and my boss isn't even qualified to appraise my performance, shouldn't I be getting paid more?) To most muscle-building program participants, this was not a pressing issue and Eichenfield believes that it is a short-term problem on the whole. However, one must wonder what the long-term career path for a muscle builder looks like. Still in the relative infancy of its muscle-building program, GFC has yet to address this issue. Program participants also questioned what the career implications of declining to participate in the program might be, though one participant did so and was invited again a year later.

The flip side of the career coin concerns the effects of muscle building on the careers of non-participants. Concerns were voiced that an employee whose immediate boss is a muscle builder might not be able to get promoted into the boss's slot-the perception being that the slot is relegated to the muscle-building rotation. That means the next level of employees at GFC below the muscle builders may perceive career gridlock precisely for the reason that their immediate supervisors do not; the supervisors are in a job rotation pattern that takes up all those jobs. This suggests that muscle building may be perceived as zero-sum by some employees: What is gained for the managers is lost for their subordinates. Though Eichenfield emphatically denies that jobs are set aside in this way, perceptions of this sort would reduce some of the benefits realized by the program. To formally alleviate this problem, discussions already are underway at GFC to consider extending the program throughout the organization by creating multiple levels of job rotation.

A final issue of note in GFC's muscle-building program is that of uncertainty and information-sharing within GFC about the program. Many organizations favor keeping secret their list of HIPOs. ${ }^{26}$ By doing so, they hope to avoid the "Crown Prince Syndrome" - that is, the creation of an elite class among managers. ${ }^{27}$ At GFC, it is no secret who the muscle builders are, and Eichenfield sees this public recognition as a form of reward that acknowledges the muscle builders' value.

Eichenfield also has made it clear that selection into the program is based on merit and visibility. The initial memo notes that the best way to become a muscle builder is to have outstanding performance and to make your outstanding performance visible-for instance, by volunteering to do more than your job requires. It was equally clear discussing the program with Eichenfield, the program participants and non-participants that there remains an aura of mystery about muscle building at GFC. One participant commented that Eichenfield likes people to wonder "just what will happen next," and that he enjoys surprising muscle builders with their new assignments. No doubt some of this ambiguity is strategic. A little mystery in the selection criteria may lead hard-chargers to do more and more to get noticed; uncertainty about the time horizons of new assignments encourages muscle builders to face up to their new jobs as at least semi-permanent. 
Muscle building: Some Final Thoughts

Edgar S. Woolward, Jr.'s, climb to the top spot at DuPont took him through twenty different jobs in thirty-two years. ${ }^{28}$ Most organizational researchers agree that experiencing a wide variety of jobs (as DuPont's CEO did) may be important, if not essential, to grooming top management talent. ${ }^{31}$ In the 1990s slow-growth environment, however, leaner corporations simply can no longer continually promote their best people through the full range of managerial experiences. Greyhound Financial's muscle-building program offers an alternative.

In 1985 , the pre-tax revenues per employee at GFC were about $\$ 55,000$; by 1989 , pre-tax revenues per employee had risen to $\$ 242,500$. Net income during the same period rose from $\$ 12.1$ million to $\$ 23.7$ million. GFC was prospering and changing when it began its muscle-building efforts, and attrition among its managerial ranks may be low in part because people like living in Phoenix and GFC pays well. However, Eichenfield realizes that the rate of change at GFC is slowing and the company is small, so the potential for career plateauing is real. He views muscle building with an eye to the future development and retention of GFC's top management team. Particularly in service organizations, highly motivated and well-developed managerial personnel are key corporate resources. In its muscle-building program, GFC appears to have found an effective way to build and stockpile those resources.

\section{Endnotes}

\footnotetext{
${ }^{1}$ J. Castro, "Where Did the Gung-Ho Go?" Time, September 11, 1989, 52-56.

2 J. Weber, "Farewell Fast Track," Business

Week, December 10, 1990, 192-200.

${ }^{3}$ Castro.

${ }^{4}$ Weber.

${ }^{5}$ Ibid.

${ }^{6}$ J.E. Ellis, "Feeling Stuck at Hyatt? Create a

New Business," Business Week, December 10. 1990, 195.

7 Weber.

${ }^{8}$ B.G. Posner, "Role Changes," Inc., February 1990, 95-98.

${ }^{9}$ W. Kiechel III., "High Up and Nowhere To

Go," Fortune, August 1, 1988, 229-231.

${ }^{10}$ B. Angelo, "Musical Chairs in Maryland," Time, August 26, 1991, 21.

"Weber.

12 A.E. Pearson, "Muscle-build the

Organization," Harvard Business Review, July/August 1987, 49-55.

${ }^{3}$ Z.B. Leibowitz, B.L. Kaye, \& C. Farren "What To Do About Career Gridlock," Training and Development Journal, April 1990, 28-35.

${ }^{14}$ C.B. Derr, C. Jones, \& E.L. Toomey,

"Managing High-Potential Employees: Current

Practices in Thirty-three U.S. Corporations,"

Human Resource Management, 27, 273-290.

${ }^{15}$ Ibid.

${ }^{16}$ See D.T. Hall, "Project Work as an Antidote to Career Plateauing in a Declining Engineering Organization," Human Resource Management, 24, 1985, 271-292; and Leibowitz, et $\alpha$ l.

${ }_{17}$ J.M. Bardwick, The Plateauing Trap (New

York: AMACOM, 1986); and Leibowitz, et al.

${ }_{18}$ R.M. Kanter, Men and Women of the

Corporation (New York: Basic Books, 1977).

${ }^{19}$ C.R. Walker, \& R.H. Guest, "The Man on
}

the Assembly Line," Harvard Business Review. 38, 1952, 71-83.

${ }^{20}$ Derr, et al

${ }^{21}$ J.R. Gailbraith, "Designing the Innovating

Organization," Organizational Dynamics.

Winter 1982, 5-25.

${ }^{22}$ For example, see: R.M. Kanter, "When a Thousand Flowers Bloom: Structural,

Collective, and Social Conditions for Innovation in Organizations," in B. Staw \& L. Cummings

(Eds.), Research in Organizational Behavior, 10 , (Greenwich, CT: JAI Press, 1988), 162-211; or C.E. Shalley, "Effects of Productivity Gools, Creativity Goals, and Personal Discretion on Individual Creativity," Journal of Applied Psychology, 76, 1991, 179-195.

${ }^{23}$ S.D. Friedman, "Succession Systems in Large Corporations: Characteristics and Correlates of Performance," Human Resource

Management, 25, 1986, 191-213.

${ }^{24}$ Derr, et al.

25 J.E. Rosenbaum, "Tournament Mobility:

Career Patterns in a Corporation,"

Administrative Sciences Quarterly, 24, 1979. 220-241.

${ }^{26}$ Derr, et al.

${ }^{27}$ D.T. Hall, "Dilemmas in Linking Succession Planning to Individual Executive Learning." Human Resource Management, 25, 1986.

235-265.

${ }^{28}$ Weber.

${ }^{29}$ T.V. Bonoma, \& J.C. Lawler, "Chutes and Ladders: Growing the General Manager," Sloan Management Review, Spring 1989, 27-37.

The authors are indebted to Greyhound Financial Corporation's top management team, particularly Sam Eichenfield and Teresa Mortensen, for their enthusiastic and insightful cooperation in writing this paper. 
About the Authors
Gregory B. Northcraft is professor of management \& policy at the University of Arizona. He received his Ph.D. in social psychology from Stanford University. His primary areas of research interest include decision behavior, conflict management, and employee motivation and job design, particularly in high-technology settings. Professor Northcraft has authored and coauthored a variety of research articles, books, and book chapters on these and related topics in organizational behavior.

Terri L. Griffith (Ph.D., Carnegie Mellon University, organizational psychology and theory) is an assistant professor of management and policy at the University of Árizona. Her primary research interests are in the application of social psychological theories to the implementation and effective use of new technology. Her current research focuses on cognitive issues in the implementation of new technology, the effective and appropriate use of computer monitoring and feedback, and the role of facilitators in group decision support systems.

Christina E. Shalley is assistant professor of management and policy at the University of Ârizona. She received her Ph.D. in business administration from the University of Illinois at Urbana-Champaign. Her current research interests include investigating the effects of contextual factors on creativity in organizations, and examining the boundary conditions of goal setting. Her research has appeared in the Academy of Management Journal, Journal of Applied Psychology, and Organizational Behavior and Human Decision Processes. 